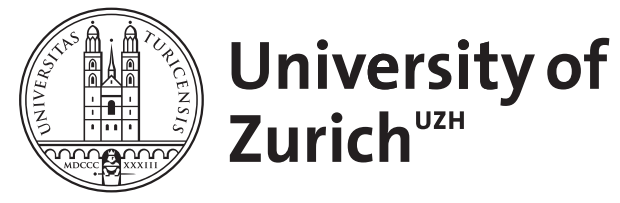

\title{
"Thrombolysis" by a neuromuscular blocking agent
}

Pascale, Patrizio ; Quartenoud, B

DOI: https://doi.org/10.1007/s00392-006-0357-z

Posted at the Zurich Open Repository and Archive, University of Zurich ZORA URL: https://doi.org/10.5167/uzh-155728

Journal Article

Published Version

Originally published at:

Pascale, Patrizio; Quartenoud, B (2006). "Thrombolysis" by a neuromuscular blocking agent. Clinical Research in Cardiology, 95(4):204-205.

DOI: https://doi.org/10.1007/s00392-006-0357-z 
P. Pascale

B. Quartenoud

\section{"Thrombolysis"}

by a neuromuscular blocking agent
A 72-year-old man was brought to our intensive care unit for a community-acquired pneumonia complicated by septic shock with multiple organ failure. Mechanical ventilation was initiated upon admission. Three days later, the patient developed striking ST segment elevation on electrocardiogram raising concern of an ongoing cardiac event (Fig. 1). However, no hemodynamic repercussion was present. Serum electrolytes were normal.

A further electrocardiogram provided evidence of a noncardiac electrical activity with a baseline undulation of the electrocardiogram asynchronous with

Received: 16 November 2005

Accepted: 25 November 2005

Published online: 27 February 2006

Patrizio Pascale, MD · B. Quartenoud, MD

Division of Cardiology

Department of Internal Medicine

University Hospital Zurich

8091 Zurich, Switzerland

Tel.: + 41-442551111

Fax: + 41-4 42554251

E-Mail: patrizio.pascale@usz.ch

Authors' institutions:

Intensive Care Unit

Cantonal Hospital

Fribourg, Switzerland

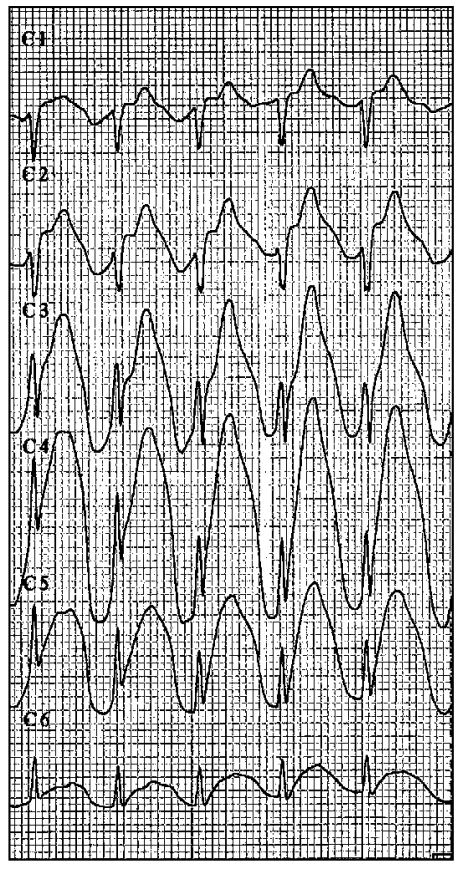

Fig. 1

the regular superimposed QRS complex (Fig. 2). The electrocardiogram normalized after administration of a neuromuscular blocking agent for the ventilatory management of the acute respiratory distress syndrome (Fig. 3). The echocardiogram performed subsequently showed diaphragmatic myoclonus at a frequency similar to the heart rate [1-3]. On the first electrocardiogram performed, the superimposed electromyographic activity of the diaphragmatic flutter was incidentally in phase with the QRS complex and had therefore been misinterpreted as cardiac electrical activity. 
Fig. 2

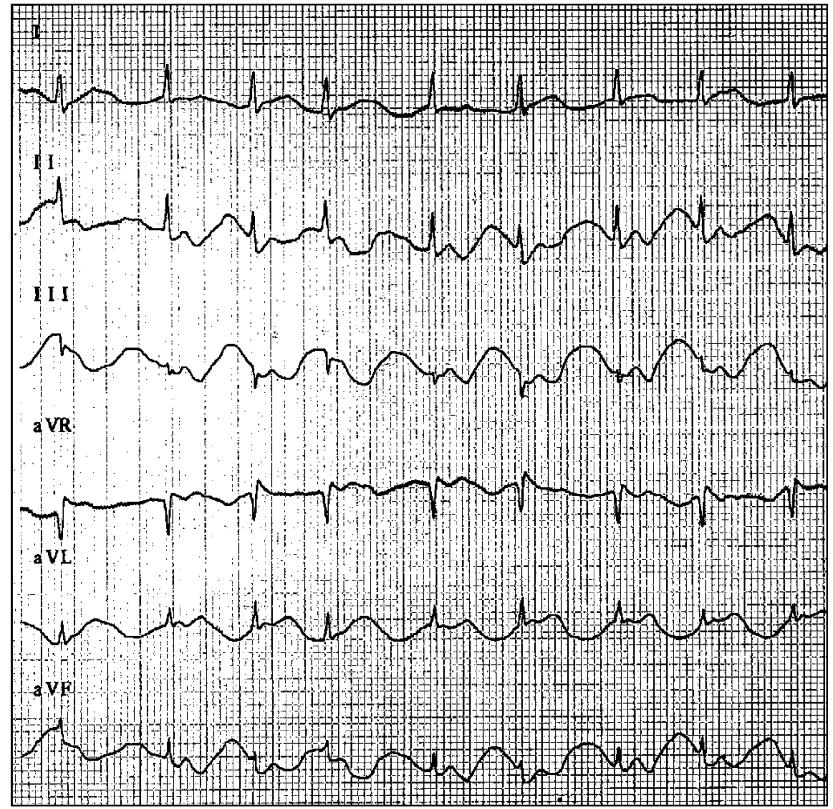

Fig. 3

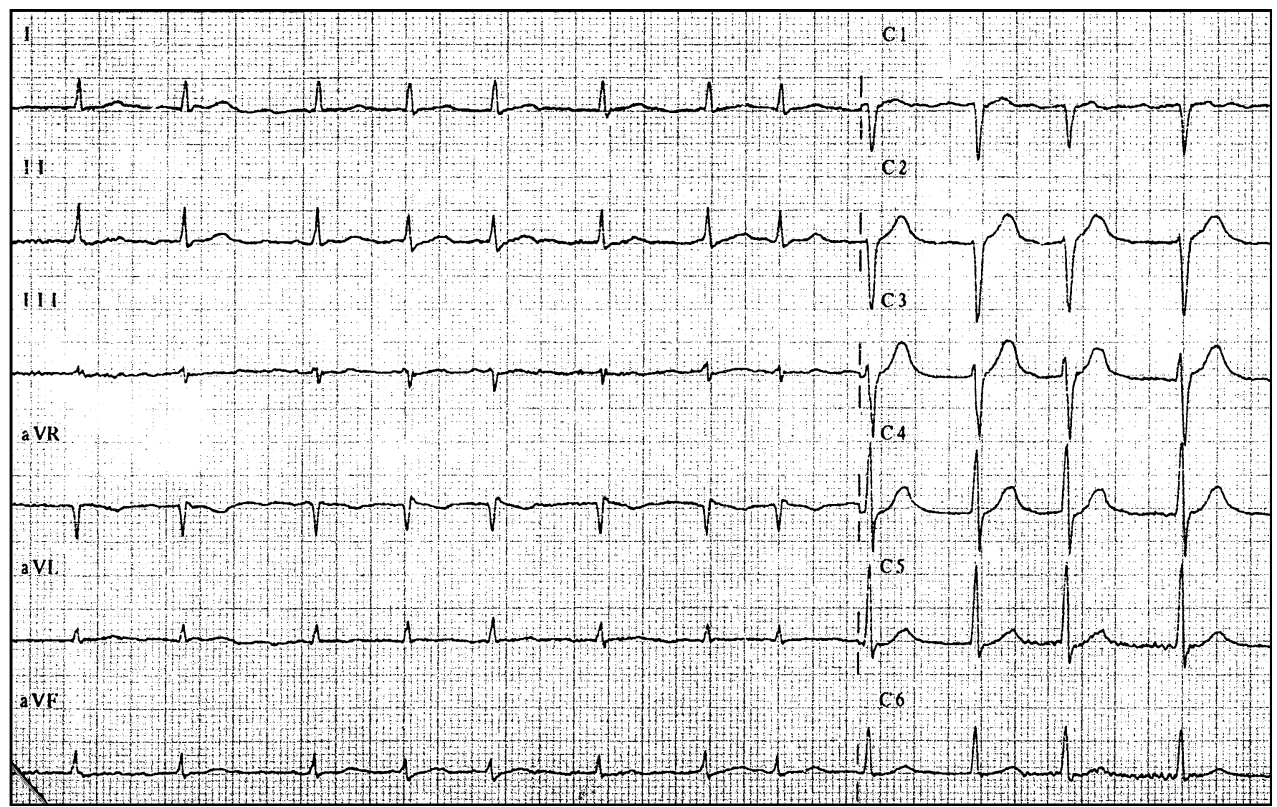

\section{References}

1. Rigatto M, De Medeiros NP (1962) Diaphragmatic flutter: report of a case and review of the literature. Am J Med 32:103-109
2. Cvietusa PJ, Nimmagadda SR, Wood R, Liu AH (1995) Diaphragmatic flutter presenting as inspiratory stridor. Chest 107:872-875
3. Hoffman R, Yahr W, Krieger B (1990) Diaphragmatic flutter resulting on failure to wean from mechanical ventilator support after coronary artery bypass surgery. Crit Care Med 18:499-501 